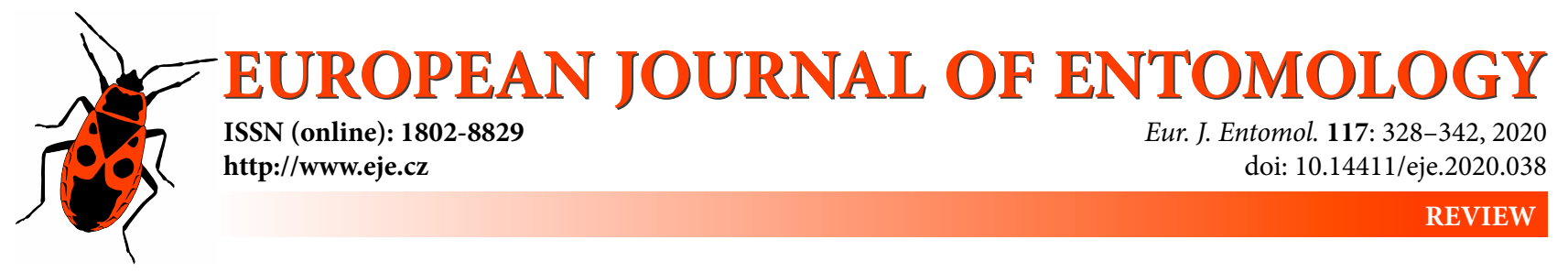

\title{
Insect photoperiodism: Seasonal development on a revolving planet ${ }^{*}$
}

\section{DAVID SAUNDERS}

\section{1, Leadervale Road, Edinburgh EH16 6PB, Scotland, United Kingdom**; e-mail: david59.saunders@mypostoffice.co.uk}

Key words. Insects, photoperiod, diapause, quiescence, time measurement, latitude, circadian, damping oscillators

\begin{abstract}
This review starts by comparing photoperiodic diapause with non-photoperiodic quiescence in four representative species, paying particular attention to overwintering in Drosophila melanogaster. In the second part it describes dormancy strategies of insects from the equator to the polar regions, addressing topics such as the role of the circadian system in photoperiodic time measurement, latitudinal clines in diapause-related traits, hourglass-like photoperiodic clocks based on dampening circadian oscillators, and the dormancy strategies of insects close to the equator or at high latitudes where seasonal changes in photoperiod are unreliable or absent.
\end{abstract}

\section{INTRODUCTION}

Insects have evolved on a planet that revolves on its axis every $24 \mathrm{~h}$ and completes its orbit around the Sun in a little more than 365 days. The former gives rise to the daily light-dark cycles that regulate (entrain) endogenous physiological and behavioural circadian rhythms. The latter gives rise to annual changes in daylength at different latitudes because the axial inclination of the Earth to the 'perpendicular' is about $23.5^{\circ}$ and, as the Earth orbits the Sun, the face of the Earth presented to the source of radiation varies. During summer in the Northern Hemisphere the sun appears to be more directly overhead, days lengthen with increasing latitude until polar regions are in constant light, whereas in the Southern Hemisphere it is winter, and days shorten with latitude. During the northern winter (and southern summer) the opposite latitudinal effects are evident. These seasonal and latitudinal changes in photoperiod are important regulators of insect development and reproduction and form the subject matter of this review.

Insects, being 'cold-blooded', show temperature-dependent metabolic control of activity, development and reproduction. In populations inhabiting temperate zones with marked seasonal variations in temperature, most insects confine their development and reproduction to the summer months but frequently enter a period of dormancy as temperatures fall in the autumn and winter. Traditionally, such dormancies have been regarded as either diapause or quiescence, and since insects that fail to become dormant may not survive, these traits provide enormous selective advantage.

In quiescence, insects respond directly to adverse environmental factors such as low temperature (i.e. cold torpor) or dehydration and are rapidly reactivated upon removal of these factors (Henneguy, 1904). In diapause, however, insects respond to 'token' stimuli, not in themselves adverse (Lees, 1955), such as the seasonal changes in photoperiod described above; these factors act well in advance of winter and provide time for the accumulation of the metabolites (lipids and proteins) needed during the dormant phase. Sometimes diapause is associated with an acquired cold tolerance (Horwath \& Duman, 1982, 1983; Lee \& Denlinger, 1991) and since it also occurs at a species-specific stage of development (e.g. in egg, larva, pupa or adult) may engender mutual synchrony within the population that facilitates mating success after reactivation in the spring.

Quiescence and diapause often involve similar 'downstream' reactivation pathways, either the brain (PTTH)prothoracic gland (ecdysteroid) axis in the regulation of larval and pupal (i.e. developmental) dormancies, or the brain-corpus allatum (juvenile hormone) axis in adult (i.e. reproductive) dormancies (Denlinger, 1985). They differ, however, in their 'upstream' control: diapause is regulated by a brain-centred photoperiodic clock measuring day- or nightlength and considered by many authors to be based

\footnotetext{
* Note: When reviewing early papers or more general accounts of photoperiodism, the terms daylength, short days, long days, critical daylength (CDL) etc are used (probably because we humans are a day-active species). In later examples, where duration of the dark phase of the daily cycle has been shown to be more important, references are made to nightlength (critical nightlength, CNL etc), hopefully without causing confusion.

** Most of the author's research was done at the University of Edinburgh.
} 
on the circadian system (Bünning, 1936, 1960; Saunders, 2020), whereas quiescence is not clock-controlled, responding directly to the adverse conditions outlined above without a comparable form of time measurement.

This review is in two parts. In the first, the roles of quiescence and photoperiodic diapause are examined in the dormancy programmes of four representative temperatezone insect species or taxa. These examples are reviewed separately because they present as many differences as similarities; particular attention is paid to dormancy in the fruit fly, Drosophila melanogaster. In a wider context the review then considers possible historical changes in the evolution of insect dormancy programmes. In doing so, it addresses the following questions: How have insects adapted their seasonal development to local climatic factors? How have they adapted to seasonal changes as their geographical distributions extended into higher latitudes? What is the nature of the photoperiodic clock, particularly its relationship to the circadian system? And how do diapause and quiescence regulate insect seasonality close to the equator or at latitudinal extremes where photoperiod becomes unreliable?

\section{DORMANCY RESPONSES OF REPRESENTATIVE INSECTS}

In many species there is evidence that diapause and quiescence operate together as components of the dormancy programme. In the European corn borer Ostrinia nubilalis (McLeod \& Beck, 1963), for example, larvae enter diapause as days shorten (or nights lengthen). Systematic transfer of diapausing larvae from the field to the laboratory showed that diapause was 'completed' soon after midwinter (even before the onset of the hardest frosts) and dormancy was then only terminated after a period of postdiapause quiescence when temperatures rose in the spring. Similar examples are to be found in at least six insect orders and mites (references in Tauber et al., 1986), including Pyrrhocoris apterus (L.) (Hodek, 1971) considered below.

\section{Pyrrhocoris apterus (Heteroptera: Pyrrhocoridae)}

The linden bug, P. apterus is widespread in Europe clustering under lime trees (Tilia cordata), often in large numbers. In central Europe (Bohemia) overwintered bugs lay eggs in May and the nymphs spend the summer months feeding on fallen lime seed, adults entering a facultative reproductive diapause in the autumn in response to short days (Hodek, 1968). Diapausing bugs then pass the winter amongst leaf litter. By transferring field-collected diapausing bugs at intervals during the winter to laboratory conditions, Hodek (1971) showed that diapause ended (i.e. 'diapause development' was completed) in the field by the end of December and bugs then remained in a cold-induced reproductive quiescence until April when temperatures rose and further development could proceed. Diapause was therefore a purely autumnal phenomenon preventing untimely reproduction during the autumn and early winter, and overwintering physiology of the dormancy programme comprised both diapause (sensu stricto) and quiescence (direct inhibition of development by low temperature).
These field studies were replicated under laboratory conditions (Saunders, 1983). When newly diapausing bugs were exposed to a range of photoperiods at $25^{\circ} \mathrm{C}$, short days were shown to maintain the diapause state. However, transferring diapausing bugs into low temperature $\left(4^{\circ} \mathrm{C}\right)$ and constant darkness for $4,6,8,10,12$ or 16 weeks before returning them to a range of photoperiods at $25^{\circ} \mathrm{C}$ showed that the diapause-maintaining effects of short days only continued for about 8 weeks, diminished by 12 weeks and then fully disappeared by 16 weeks. Laboratory studies were therefore in agreement with Hodek's earlier data using field-collected material.

\section{Nasonia vitripennis (Hymenoptera: Pteromalidae)}

The parasitoid $N$. vitripennis enters a larval diapause at the end of the fourth (final) instar in response to short days. However, unlike $P$. apterus in which photoperiodic sensitivity occurs in the nymphal stages immediately preceding the adult (reproductive) arrest, the sensitive period in $N$. vitripennis is maternal and the larvae themselves do not respond to short days (Saunders, 1965, 1966). Given a daily supply of fresh host blow fly pupae, wasp females oviposit daily; each day's progeny, either diapause or nondiapause, thereby reflects the physiological state of the adult wasp on the day of oviposition. Under long days wasps produce almost all their offspring as nondiapause larvae. Under 'strong' short days, however, wasps produce nondiapause larvae during the first few days of adult life and then switch abruptly to the production of diapausing larvae, the 'switch point' occurring after a so-called 'required day number' or RDN (Saunders, 1966). Under strong short daylengths the $\mathrm{RDN}$ is temperature compensated $\left(\mathrm{Q}_{10}\right.$ about 1.04$)$ whereas the duration of reproductive life and the rate of egg production are both temperature dependent $\left(\mathrm{Q}_{10}\right.$ between 2 and 3$)$; consequently the proportion of the progeny entering diapause is greater at lower temperatures (Saunders, 1966). Wasps maintained in constant darkness give rise to a variable proportion of diapausing larvae that is also greater at lower temperature, suggesting that chilling alone is also a diapause-inducing factor (Schneiderman \& Horwitz, 1958). These data show that the diapause programme in $N$. vitripennis includes two inter-related processes: (1) day- or nightlength measurement (or both) and (2) a mechanism accumulating and storing the inducing effects of successive photoperiods; this combination comprises a diapauseinducing 'clock-counter' mechanism (Saunders, 1981).

De Loof et al. (1979) showed that larval diapause in $N$. vitripennis may be terminated by application of 20-hydroxyecdysone, suggesting that it is regulated by the PTTHecdysone 'pathway'. Although nondiapause development occurs within a few weeks in $N$. vitripennis, Schneiderman \& Horwitz (1958) showed that diapausing larvae kept at temperatures above about $15^{\circ} \mathrm{C}$ may remain dormant for months. Exposure of diapausing larvae to temperature as low at $2{ }^{\circ} \mathrm{C}$ for about 8 weeks or more, followed by a transfer to higher temperature, however, led to reactivation of development. Termination of the diapause programme, therefore, may involve a period of diapause development followed by post-diapause quiescence, as in P. apterus. 


\section{Sarcophaga spp. (Diptera: Sarcophagidae)}

Flesh flies enter a pupal diapause induced by autumnal short days (or long nights) (Denlinger, 1971; Saunders, 1971). In S. argyrostoma (Robineau-Desvoidy) response to photoperiod starts in the intra-uterine embryos within the gravid female and continues, with declining sensitivity, through to the wandering larvae that enter the soil to pupate, a stage in development that effectively indicates the end of the photoperiodic 'sensitive period' (Saunders, 1971). During this period the embryos and larvae 'measure' the length of the night phase of the daily light-dark cycle and simultaneously integrate successive long nights in a temperature-compensated manner using a photoperiodic 'counter' (Saunders, 1971, 1981, 1992) similar to that described above for $N$. vitripennis. Other species of Sarcophaga show slight variations in their sensitive periods. In $S$. crassipalpis and $S$. bullata maximum sensitivity is in the intrauterine embryos and feeding larvae are insensitive (Denlinger, 1971) whereas in Japanese populations of $S$. similis, as with $S$. argyrostoma, larval sensitivity extends as far as the post-feeding $3^{\text {rd }}$ instar larva just before pupariation (Goto \& Numata, 2009).

Diapausing pupae of Sarcophaga species pass the winter in the soil and undergo processes (diapause development) leading to eventual completion of the dormancy programme by the spring. In central Illinois, the first postdiapause adults of $S$. bullata emerge during mid-May, produce several summer generations and then enter diapause by September after a critical daylength of about $13.5 \mathrm{~h} / 24$ has been passed (Denlinger, 1972a, b). These diapausing pupae are capable of prompt reactivation upon transfer to $25^{\circ} \mathrm{C}$ but within the soil remain in post-diapause quiescence during the remaining cold winter months, eventually to resume development in April. Like P. apterus, therefore, the overwintering dormancy programme comprises both diapause and a phase of post-diapause quiescence.

\section{Drosophila melanogaster (Diptera: Drosophilidae)}

The fruit fly, D. melanogaster, is of Afro-tropical origin (Lemeunier et al., 1986) but has since achieved an almost world-wide distribution. However, unlike some other drosophilids (Lumme, 1978) it has never established itself in far-north field localities. In temperate regions further to the south, the species overwinters by taking refuge in sheltered locations - often as a human commensal - in a reproductive dormancy accepted by early authors as a low-temperature induced quiescence (e.g. Roberts, 1985; Izquierdo, 1991; Bouletreau-Merle et al., 2002). Only adult flies were reported to overwinter in this condition (Izquierdo, 1991).

However, working with a long-established laboratory strain of D. melanogaster (Canton-S), it was shown that transferring newly emerged flies into a range of light-dark cycles at $12^{\circ} \mathrm{C}$ resulted in those females exposed to short days (less than about $14 \mathrm{~h}$ of light per day) delaying ovarian maturation for about 6 to 7 weeks, whilst those exposed to longer days at the same temperature underwent some egg development (Saunders et al., 1989). Initially, this condition was identified as 'reproductive diapause' because (1) it occurred at a specific stage of development (the adult fly), (2) was regulated by the titre of juvenile hormone produced by the corpora allata (Saunders et al., 1990), and (3) because of an apparent 'critical daylength' between short and long days suggesting some sort of time measurement by a photoperiodic clock. However, although the delay in ovarian maturation persisted for about 6 to 7 weeks under a $10 \mathrm{~L}$ : $14 \mathrm{D}$ cycle at $12^{\circ} \mathrm{C}$ it was readily terminated by a transfer to longer days, or to a higher temperature, suggesting that the response was 'weak' or 'shallow', thereby presenting characteristics of both diapause and quiescence. Subsequently, authors (see below) have variously referred to this condition as quiescence, diapause or diapause-like quiescence.

The probable selective advantage of this overwintering dormancy in D. melanogaster is attested by studies showing latitudinal clines in the expression of the diapause or quiescence response. Using 12 populations of flies isolated in orchards from Florida to Maine (a range of latitudes from about 25 to $44^{\circ} \mathrm{N}$ ), and then exposing them to a $10 \mathrm{~L}: 14 \mathrm{D}$ cycle at $12^{\circ} \mathrm{C}$, Schmidt et al. (2005) recorded a robust south-to-north cline, increasing from about 35 per cent of dormancy in Florida to about 85 per cent in the north. A comparable latitudinal cline is suggested for populations of $D$. melanogaster in Australia from 16 to $42^{\circ} \mathrm{S}$ (Mitrovski \& Hoffmann, 2001) but is less compelling for flies in Europe (Pegararo et al., 2017).

In order to address the question whether temperature or light (photoperiod) was the most important dormancyinducing factor in D. melanogaster, Emerson et al. (2009) collected samples of flies from fruit growing areas in Florida $\left(27^{\circ} \mathrm{N}\right)$ and Maine $\left(44^{\circ} \mathrm{N}\right)$ and subjected them to either long days $(18 \mathrm{~L}: 6 \mathrm{D})$ or short days $(10 \mathrm{~L}: 14 \mathrm{D})$ at a range of temperatures between 10 and $14^{\circ} \mathrm{C}$. Illumination was provided by light-emitting diodes (LEDs) creating only $0.2 \mathrm{~W}$ of heat - less than that produced by the fluorescent strip-lights frequently provided in commercial incubators, such as those used earlier by Saunders et al. (1989). Emerson et al. (2009) showed that ovarian dormancy was more frequent in flies from Maine, and that temperature was the main factor determining dormancy, whilst photoperiod had no such effect. This suggested that ovarian dormancy in D. melanogaster was an example of low-temperature quiescence rather than diapause. In the earlier investigation using Canton-S flies (Saunders et al., 1989), insects exposed to long days probably experienced a greater total exposure to the slightly elevated temperature produced by the fluorescent strip-lights. Consequently, the apparent 'critical daylength' referred to above was probably the result of cumulative effects of slight increases in temperature during the photophase and not to time-measurement by a photoperiodic 'clock' (see also discussion below, and Saunders, 2008).

Although dormancy in North American strains of D. melanogaster appeared to be a low-temperature induced quiescence, studies with European flies have indicated some diapause-like features. In these studies, attention was paid to the relative importance of temperature and light (pho- 
toperiod) as inducing factors for overwintering dormancy, and to the type of light source used in the experiments.

Anduaga et al. (2018) exposed flies to long (16L:8D) or short daylength $(8 \mathrm{~L}: 16 \mathrm{D})$ with or without a concurrent temperature cycle $\left(12^{\circ} \mathrm{C}\right.$ when the lights were off and $12 \pm 0.3^{\circ} \mathrm{C}$ when the lights were on). Flies were assessed for ovarian dormancy after 12 days. When the temperature cycle was present significantly more dormancy was produced under short days, but this effect did not occur when the temperature cycle was removed. When the phase relationship between light and temperature was reversed more dormancy was observed under long days. The authors concluded that (low) temperature was the principal factor inducing dormancy in D. melanogaster, but photoperiod had a significant effect, short days enhancing the effect of low temperature. In a later paper, Nagy et al. (2018) exposed flies from Italy and Holland to simulated summer and autumnal lighting profiles, progressively changing in duration. Induction of ovarian dormancy in these groups was then compared with those exposed to conventional squarewave light-dark cycles at a temperature of $12^{\circ} \mathrm{C}$. This seminatural approach showed that flies exposed to simulated autumnal days produced a higher proportion of dormancy than those in corresponding square-wave cycles, and those under simulated summer days produced less. Simulation of natural cycles of light therefore enhanced or reduced the dormancy response, suggesting that light was an important factor: but was it a 'true' photoperiodic response?

Using six populations of $D$. melanogaster from sites ranging from southern Spain to Finland, Pegoraro et al. (2017) exposed flies to 6 photoperiods $(8 \mathrm{~L}: 16 \mathrm{D}$ to $18 \mathrm{~L}: 6 \mathrm{D})$ at a temperature maintained at $12.5 \pm 0.3^{\circ} \mathrm{C}$, and constructed dormancy response curves for each strain. Each of these curves showed a slight increase in the proportion of flies becoming dormant under shorter days, but logprobit transformation of the data showed, at best, a gentle curvilinear relationship between the proportion of flies becoming dormant and daylength, without a marked 'critical daylength' between short and long days that is so characteristic of insects with a well-marked photoperiodic response and a defining feature of diapause, s. str. Evidence suggests, therefore, that the dormancy response in D. melanogaster in European populations is a low-temperature induced quiescence rather than a true diapause, albeit with intriguing elements suggesting some diapause-like qualities.

Exposure of short period $\left(\right.$ per $\left.^{\mathrm{s}}\right)$ and long period $\left(\mathrm{per}^{\mathrm{L}}\right)$ mutant flies to a range of photoperiods at $12^{\circ} \mathrm{C}$ produced identical response curves that resembled apparent 'critical daylengths' (CDLs) (Saunders, 1990). At first, this suggested that per was not causally involved in a photoperiodic clock - thereby regulating a true 'diapause' response - since changes in circadian period should theoretically have marked effects on CDL, as suggested by a circadianbased photoperiodic model (Saunders \& Lewis, 1987a). It should be noted here that no PER or TIM staining could be demonstrated in the brains of $D$. melanogaster at $12^{\circ} \mathrm{C}$ (Menegazzi et al., 2013). The apparent CDLs reported by Saunders (1990), therefore, were probably artefacts of un- controlled changes in temperature (see above). An alternative explanation is possible: Mutant circadian periods have no effect on CDL because the dormancy response in question is a low-temperature quiescence, and not diapause.

\section{Diapause and quiescence as separate components of the insect dormancy programme}

The first section of this review shows that both diapause and quiescence contribute to the seasonal regulation of insect development and reproduction. The second section examines the seasonal and geographical changes in dormancy patterns.

Several early models for the evolution of insect dormancy (e.g. Mansingh, 1971; Tyshchenko, 1966) suggested that diapause had its origin in quiescence. Whilst this is possible, it is more likely that diapause and quiescence are distinct phenomena and have been so since insects first evolved in Devonian swamps. Consequently the origin of photoperiodic diapause probably occurred at a much earlier time as a function of an extremely ancient lineage giving rise to endogenous circadian rhythmicity, and is present in taxa as diverse as fungi, green plants, birds and mammals (Nelson et al., 2010). By comparison with overt behavioural rhythms, diapause induction resembles endogenous control by the circadian system entrained by token stimuli, whereas quiescence is more akin to the exogenous or direct 'masking' effects of adverse environmental factors. It is probable that insects first appeared during the Devonian era in climates suitable for continuous or homodynamic development and spread from there into higher latitudes. Changes engendered by this spread are examined below.

\section{DORMANCY PROGRAMMES AND LATITUDE}

\section{Dormancy in the Tropics and Subtropics}

The tropics are formally defined as those lands lying between the Tropic of Cancer $\left(23.5^{\circ} \mathrm{N}\right)$ and the Tropic of Capricorn $\left(23.5^{\circ} \mathrm{S}\right)$. Close to the equator (roughly $10^{\circ} \mathrm{N}$ to $10^{\circ} \mathrm{S}$ ) seasonal changes in daylength are slight or virtually absent and many insects show homodynamic or continuous development without dormancy. Examples of such life cycles are afforded by Polionemobius (= Pteronemobius spp.) ground crickets from various parts of tropical southeastern Asia $\left(8^{\circ} \mathrm{S}\right.$ to $\left.10^{\circ} \mathrm{N}\right)$ which show no egg diapause in response to photoperiod (Masaki et al., 1987). In other areas close to the equator dormancies do occur, but it is not always certain that they are 'true' photoperiodic diapauses or merely forms of quiescence. There are few records of insects that can cope with such small changes in photoperiod; many more respond to environmental stimuli other than daylength such as temperature, humidity or biotic factors (Denlinger, 1986).

However, flesh flies living at altitude in Kenya produce about 7 generations annually with a facultative diapause occurring during July and August, the coldest months of the year (Denlinger, 1978). Diapause in these flies occurs in the pupa and like their temperate-zone counterparts reviewed above, is regulated by the brain-prothoracic gland axis (Denlinger, 1979). In Nairobi, Kenya $\left(1^{\circ} \mathrm{S}\right)$, the annual 
variation in daylength is only about $\pm 7 \mathrm{~min}$, insufficient to act as a signal for diapause induction. In five sarcophagid species (Sarcophaga par, S. inzi, S. exuberans, Poecilometopa spilogaster and P. punctipennis), however, flies were shown to enter pupal diapause in response to low temperature experienced during larval development. Furthermore, cool daytime temperature was shown to be more diapause inductive than cool nights, suggesting that thermoperiod was acting as a seasonally appropriate token stimulus in place of photoperiod.

There are at least two examples of equatorial insects using annual changes in daylength to synchronise their life cycles to the seasons. Norris $(1962,1965)$ showed that the red desert locust Nomadacris septemfasciata (whose normal habitats in Africa are between $7^{\circ} \mathrm{S}$ and $16^{\circ} \mathrm{N}$ ) entered an intense reproductive diapause when the nymphs experienced long days (about $13 \mathrm{~h}$ per day) but the adults a short day (about $12 \mathrm{~h}$ ). Conversely, nondiapause development followed nymphal development under a $12 \mathrm{~h}$ photoperiod and the adults under $13 \mathrm{~h}$. In its natural environment this response enabled the species to synchronise its development to an exact year, reproducing during the rains but entering diapause during the winter drought. Sequences of daylength also proved to be important for regulating reproductive diapause of the fungus beetle Stenotarsus subtilis in Panama $\left(9^{\circ} \mathrm{N}\right)$ (Wolda \& Denlinger, 1984). Diapausing beetles form dense aggregations consisting of thousands of individuals remaining in diapause for up to 10 months, showing reduced metabolism, degeneration of flight muscles and fat body hypertrophy. Tanaka et al. (1987, 1988) showed that the major factor involved in diapause induction and termination was photoperiod, with no gonad growth occurring under a $12 \mathrm{~h}$ photoperiod but, as days lengthened to $13 \mathrm{~h}$ between January and April, the gonads and flight muscles developed rapidly. Here it should be noted that both $N$. septemfasciata and S. subtilis are longlived insects with a univoltine life cycle, raising the possibility that they possess an endogenous circannual clock akin to that in the temperate-zone carpet beetle, Anthrenus verbasci (Blake, 1958, 1959; Nisimura \& Numata, 2001).

Further north (or south) from the equator but still within the tropics, annual changes in daylength are somewhat greater and photoperiodic induction of diapause is more frequent. For example, pupal diapause of the noctuid $\mathrm{He}$ liothis armigera in the Sudan Gezira $\left(14^{\circ} \mathrm{N}\right)$ occurs when larvae are exposed to $12 \mathrm{~L}: 12 \mathrm{D}$ at about $22^{\circ} \mathrm{C}$, delaying further development in the hot dry season until the start of the rains (Hackett \& Gatehouse, 1982). Larval diapauses of other Lepidoptera such as the southwestern corn borer Diatraea grandiosella in southern Mexico $\left(19^{\circ} \mathrm{N}\right)$ (Kikakawa \& Chippendale, 1983), strains of the pink bollworm moth Pectinophora gossypiella (Ankersmit \& Adkisson, 1967) and the stored product pest Ephestia cautella (Bell et al., 1983) from various tropical localities, are also regulated by photoperiod.

In the northern hemisphere, the subtropics may be defined as those areas that border the tropics to the south and temperate regions to the north (roughly 20 to $35^{\circ} \mathrm{N}$ ), areas in which seasonal changes in photoperiod are greater than in the tropics, but clearly-defined summer and winter seasons are not always apparent. The subtropics include a wide variety of climatic types. Apart from some of the major deserts, these include areas with hot and humid summers mainly on the eastern edges of the continents, or areas on the western edges of continents with winter rains and dry summers (the so-called 'Mediterranean' climates). Seasonal cycles of development and dormancy in these disparate climates may be equally diverse.

The life cycles of several species inhabiting the subtropical Ryukyu islands in the southernmost Japanese archipelago have been examined for their photoperiodic responses. On Okinawa $\left(26^{\circ} \mathrm{N}\right)$, Ando (1991) found that first generation adults of the tettigonid Euconocephalus pallidus developing as nymphs under long days laid eggs without delay, whereas second generation adults, having experienced short days, entered diapause. On the other hand, the subtropical cockroach Margatta satsumana on the isolated Hachijo Island $\left(33^{\circ} \mathrm{N}\right)$ was found to enter a summer diapause induced by long days and terminated rapidly by short days, the adults passing the winter as nondiapausing adults (Zhu \& Tanaka, 2004).

In lands bordering the Mediterranean, summers are warm or hot with little rain, whereas the winters are cooler and receive most of the annual rainfall. In such areas, dormancy during the hotter, drier season (referred to as summer diapause) would naturally be expected to occur. Masaki (1980) pointed out that such dormancies are not restricted to these areas and have been recorded at latitudes up to $60^{\circ} \mathrm{N}$. Nevertheless, seasonal cycles of this type have been described for insects in these climatic areas, particularly where plants die back during the hotter and drier season; three examples are given here.

In a field study in Libya $\left(32^{\circ} \mathrm{N}\right)$, Paarman (1970) found that carabid beetles were not collected in midsummer but appeared in the autumn to breed in winter. In a subsequent laboratory study of the carabid Broscus laevigatus, Paarman (1974) found that long days (14L:10D) retarded development of the gonads, whereas long days followed by short days (10L: 14D) led to gonadal maturation. Furthermore, in continuous darkness gonadal maturation was delayed at $30^{\circ} \mathrm{C}$ but accelerated following transfer to $20^{\circ} \mathrm{C}$; these observations suggested a univoltine life cycle with a 'summer' diapause. In Israel (also at $32^{\circ} \mathrm{N}$ ), both males and females of the grasshopper Oedipoda miniata entered a reproductive diapause during the dry summer months. Using mating behaviour as an indicator of diapause in male grasshoppers, Orshan \& Pener (1979) showed that diapause was maintained under long days (14L:10D) at high temperature but terminated by transfer to shorter daylengths or lower temperature, thereby mimicking conditions in the field. These observations constituted one of the first observations on photoperiodic regulation of diapause in a male insect.

The tiger moth Cymbalophora pudica occurs in areas around the Mediterranean from North Africa and through southern Europe to Greece, with the main period of adult 
flight activity occurring in the autumn but with an occasional generation in the spring. Larval development occurs during the winter months and the dry summer months are passed in a pupal diapause (Spitzer, 1980). Based on experiments using material from the Isle of Brač, Croatia $\left(43^{\circ} \mathrm{N}\right)$, Koštál \& Hodek (1997) suggested that the univoltine life cycle occurred following a relatively cold winter when prepupae are kept in diapause by increasing daylength in the spring, but then decreasing daylength after the summer solstice synchronises pupation and the moths emerge in the autumn. When the winter is relatively warm, a proportion of the population may be diverted to become adults in May or June, thus giving rise to the bivoltine life cycle.

\section{Dormancy in Temperate Regions}

Further north, into the temperate zones, four distinct seasons are apparent, although to the south winters are short and relatively mild, whereas to the north they become longer and more severe. Conversely, with increasing latitude favourable summer 'growing seasons' become shorter and cooler. Although summer diapause occurs throughout this zone (Masaki, 1980), the commonest forms of dormancy (diapause and quiescence) occur as strategies for survival during cold winters inimical for development and reproduction. Seasonal life histories of the four representative species outlined at the start of this review indicate some of the divergent ways in which insects overwinter. In this section some of the major features of seasonal development in mid-latitude insects will be described.

\section{Prevention of maladaptive diapause in the spring}

Since diapause-inducing short days occur twice per year, in spring as well as autumn, it is theoretically possible for insects emerging from dormancy early in the spring whilst days are still short, to enter a maladaptive diapause. However, working with the flesh fly Sarcophaga bullata, Henrich \& Denlinger (1982) showed that flies emerging early from dormancy - possibly because warm weather curtails post-diapause quiescence - were incapable of producing diapausing progeny themselves, even under strong short days. Normal responses to short days only reappeared after a further generation under long days. Subsequent investigation (Rockey et al., 1989) suggested that a maternal 'message' was passed from the brain to the ovaries. A similar but less pronounced effect was observed in $S$. crassipalpis (Henrich \& Denlinger, 1982) but found to be absent in $S$. argyrostoma from more northern Europe (Kenny et al., 1992), possibly because the colder spring at higher latitudes leads to protracted post-diapause quiescence so that the appearance of the first flies in the spring is delayed until daylength exceeds its critical value. Similar phenomena enabling insects to distinguish spring from autumn have been described in aphids. Lees (1960), for example, showed that the first spring generation of Megoura viciae (emerging from diapause eggs) gave rise, under continuing short days, to successive generations of viviparous and parthenogenetic offspring which were incapable of producing the short-day morph (oviparae) for at least 90 days. The photoperiodic response was then fully restored, the short-day treatment inducing oviparae that, in turn, produced diapause eggs. A similar transgenerational timer has been recorded in the pea aphid Acyrthosiphon pisum (Matsuda et al., 2017). It is possible that mechanisms preventing a maladaptive diapause under spring photoperiods are widespread, particularly at southern latitudes where winter ends whilst daylength is still short.

\section{Latitudinal clines and other geographical effects}

Insects inhabiting different latitudes experience longer and warmer summers to the south but increasingly cold and longer winters to the north. Early work by Danilevskii and his colleagues at Leningrad (now St Petersburg) University showed that insects have evolved seasonal life cycle strategies in often well-marked latitudinal clines to cope with these climatic changes (Danilevskii, 1957, 1965). Working with populations of the knot grass moth Acronycta rumicis such a cline was demonstrated for the critical daylength (CDL) of the photoperiodic mechanism regulating pupal diapause. A population from the Black Sea coast (Sukhu$\mathrm{mi}, 43^{\circ} \mathrm{N}$ ) showed a CDL of about $14.5 \mathrm{~h}$ per 24 , whereas populations from Belgorod $\left(50^{\circ} \mathrm{N}\right)$, Vitebsk $\left(55^{\circ} \mathrm{N}\right)$ and St Petersburg $\left(60^{\circ} \mathrm{N}\right)$ showed CDLs of $16.5,18$ and 19.5 $\mathrm{h}$ per day, increasing by about $1.5 \mathrm{~h}$ per day with every $5^{\circ} \mathrm{N}$ of latitude. The selective advantage provided by this latitudinal cline was clear: in northern populations experiencing longer summer days but an earlier onset of winter the longer CDL ensured that diapause was induced before the first frosts, whereas those from the south with a shorter CDL were able to exploit the longer growing season by delaying diapause onset.

Similar latitudinal clines for CDL have been described for critical daylength in a range of species. Notable examples include the cabbage moth Mamestra brassicae (Danilevskii, 1965; 4 strains from 43 to $60^{\circ} \mathrm{N}$ ), the lacewing Chrysopa carnea (Tauber \& Tauber, 1972; 10 strains from 25 to $50^{\circ} \mathrm{N}$ ), the rice stem borer Chilo suppressalis (Kishino, 1974; 23 strains from 32 to $43^{\circ} \mathrm{N}$ ), the mosquito Wyeomyia smithii (Bradshaw, 1976; 22 strains from 30 to $49^{\circ} \mathrm{N}$ ), the psocopteran Peripsocus quadrifasciatus (Eertmoed, 1978; 15 strains from 31 to $49^{\circ} \mathrm{N}$ ), the codling moth Laspeyresia pomonella (Riedl \& Croft, 1978; 16 strains from 33 to $43^{\circ} \mathrm{N}$ ), Drosophila littoralis (Lankinen, 1986; 57 strains from 41 to $69^{\circ} \mathrm{N}$ ), the spider mite Tetranychus urticae (Vaz Nunes et al., 1990; 10 strains from 40.5 to $60^{\circ} \mathrm{N}$ ), the parasitic wasp Nasonia vitripennis (Paolucci et al., 2013; 7 strains from 42 to $65^{\circ} \mathrm{N}$ ), the flesh fly Sarcophaga similis (Yamaguchi \& Goto, 2019; 4 strains from 33 to $43^{\circ} \mathrm{N}$ ) and Drosophila montana (Tyukmaeva et al., 2020; 7 strains in Finland to $67^{\circ} \mathrm{N}$ ).

Apart from critical daylength, latitudinal effects on several other aspects of the overwintering diapause programme have been described. These include the number of generations per year (voltinism), the depth or intensity of diapause, the required day number (RDN) or switch point from nondiapause to diapause in the photoperiodic counter mechanism (Beach, 1978; Paolucci et al., 2013), and also cold hardiness (Saunders \& Hayward, 1998; Vesala \& Hoikkala, 2011). Latitudinal effects on voltinism were 
first described by Danilevskii (1965) for A. rumicis: because the 'growing season' was longer in the south, populations were found to be bivoltine or multivoltine, whereas the population from St Petersburg was univoltine. For diapause intensity, the first report was for summer diapause duration in Japanese populations of $M$. brassicae pupae in which the cline shortened progressively from $28^{\circ} \mathrm{N}$ to $44^{\circ} \mathrm{N}$ (Masaki, 1956) - an observation which appears to be the first of its kind. An example of latitudinal effects on diapause intensity in winter diapause is that for the blow fly Calliphora vicina (Saunders, 1987; McWatters \& Saunders, 1996, 1998); diapause intensity is also discussed by Masaki (2002). All these reports indicate that insects use a suite of genes to assist their distribution into more northerly latitudes. Evolutionary aspects of these photoperiodically and diapause-related clines have been considered by Hut et al. (2013).

The circadian basis of photoperiodic time measurement

A series of whole-animal experiments with the flesh fly Sarcophaga argyrostoma and its hymenopterous parasite, Nasonia vitripennis, using protocols based on the known behaviour of circadian rhythms, has produced formal evidence that photoperiodic time measurement is a function of the circadian system, as envisaged over eight decades ago by the German plant physiologist, Erwin Bünning (1936, 1960).

In $N$. vitripennis, experiments using the so-called NandaHamner (NH) protocol in which wasps were exposed to non-24 h light cycles ranging in period from 18 to $72 \mathrm{~h}$, each cycle containing a 'short' photophase (e.g. 8 to 12 $\mathrm{h}$ ), revealed peaks and troughs of diapause incidence at circadian (about $24 \mathrm{~h}$ ) intervals as cycle length increased (Nanda \& Hamner, 1958; Saunders, 1974) thereby adding support to Bünning's hypothesis (Saunders, 1974, 2020). Other experiments using daily temperature cycles (thermoperiods) in constant darkness (Saunders, 1973), or experiments involving periods of chilling during either the light or dark components of the daily cycle (Saunders, 1967, 1969), suggested the operation of a specific version of Bünning's hypothesis involving separate 'dawn' and 'dusk' oscillators, that of 'internal coincidence' (Pittendrigh, 1972) in which seasonal changes in photoperiod are sensed by changing phase relationships between the two.

Action spectrum studies on $N$. vitripennis in which a daily $13 \mathrm{~h}$ white light pulse was augmented by $3 \mathrm{~h}$ of monochromatic light of varying intensity, either just after the end of the light phase (a 'new dusk') or before it (a 'new dawn') to convert the $13 \mathrm{~h}$ short day into a $16 \mathrm{~h}$ long day, revealed broad peaks of sensitivity to wavelengths between 554 and $586 \mathrm{~nm}$, extending into the red at $617 \mathrm{~nm}$ for both pulses (Saunders, 1975a). Since the circadian 'clock' genes cryptochrome 1 and timeless 1 are both absent from the $\mathrm{Na}$ sonia genome (Rubin et al., 2006; Schurko et al., 2010), candidates for photoreception may be opsin-based photoreceptors in the compound eyes.

In the flesh fly $S$. argyrostoma, Nanda-Hamner (NH) experiments also suggested that photoperiodic induction was a function of the circadian system, although unlike $N$. vitripennis, the most appropriate version of Bünning's hypothesis was 'external coincidence' (Pittendrigh, 1972) in which a single oscillator is entrained by the daily light : dark cycle in such a way that a light-sensitive or photoinducible phase $\left(\varphi_{\mathrm{i}}\right)$ is timed to occur, late in the scotophase, at the end of the critical nightlength, or $9.5 \mathrm{~h}$ after 'dusk' (Saunders, 1978, 2020). Since the photoperiodic oscillation is set to a narrow range of phases at the beginning of the dark phase (equivalent to the beginning of the subjective night, CT 12; Saunders, 1978, 2020), the photoinducible phase $\left(\varphi_{\mathrm{i}}\right)$ must occur at CT $12+9.5 \mathrm{~h}$, or at CT 21.5. Evidence to validate this prediction will be presented below.

External and internal coincidence are not mutually exclusive: both are valid models for different species. Indeed, differences between photoperiodic clocks are to be expected given known variations in the insect circadian system, for example the absence of tim 1 and cry 1 in some species, the presence of cry 2 in others, or differences in ocular or brain photoreception.

Using S. similis, Goto \& Numata (2009) showed that monochromatic light pulses falling early in a long night show responses in the blue-green range suggesting entrainment of the oscillation via CRYPTOCHROME (CRY), whereas pulses falling late in the night, and illuminating $\varphi_{\mathrm{i}}$, show a wider response up to and including red. This suggested the operation of two distinct photoreceptors: CRY for entrainment - phase delay for the early night pulse and phase advance for the late pulse - and perhaps an opsinbased pigment at $\varphi_{i}$ for operation of the developmental switch as nightlength changes (Saunders, 2020). With the absence of eyes in Sarcophaga larvae, photoreception may be directly to the brain or to larval photoreceptors such as the Hofbauer-Buchner eyelets.

In $S$. argyrostoma the rhythm of pupal eclosion (adult emergence) and the photoperiodic oscillator display common properties. Both are entrained by light pulses during embryonic and early larval development, then show declining sensitivity to light during later feeding stages and a final loss of sensitivity coinciding with the larvae burrowing to form puparia. For the eclosion rhythm, this decline is illustrated by a change in the phase response curve from Type 0 through Type 1 to its final extinction as larval development proceeds (Saunders, 1979b). These close similarities - examples of the 'parallel peculiarities' envisaged by Minis (1965) - facilitated use of the overt eclosion rhythm as an indicator ('hands of the clock') of the otherwise covert photoperiodic oscillator in a series of experiments designed to test for an association between circadian rhythmicity and the photoperiodic phenomenon (Saunders, 1978, 2020).

To do this, a 'family' of phase response curves (PRCs) for pulse durations between 1 and $20 \mathrm{~h}$ was constructed for the $S$. argyrostoma eclosion rhythm. In a series of papers, these data were then used to compute presumed approaches to and final steady-state entrainment of the photoperiodic oscillator to complex light-dark cycles in a large series of experiments. These included Nanda-Hamner experiments, 'symmetrical skeleton' photoperiods formed 
from two short ( $1 \mathrm{~h})$ light pulses per cycle acting as 'dawn' and 'dusk', and 'asymmetrical skeleton' (or 'night interruption') experiments in which the dark phase of the lightdark cycle was systematically interrupted by a short supplementary or 'scanning' light pulse. These experiments have been extensively reviewed before (see Saunders, 1978, 1979a, 2010, 2020) and will not be considered in detail here. Of these, however, the so-called T-experiment (Saunders, 1979a) is particularly instructive. In this procedure, larvae of $S$. argyrostoma were exposed, during their photoperiodic sensitive period, to single $1 \mathrm{~h}$ pulses of light in light-dark (LD) cycles whose periods encompassed the primary range of entrainment of the photoperiodic oscillator, for example, from $1 \mathrm{~L}: 20 \mathrm{D}(\mathrm{T}=21 \mathrm{~h})$ to $1 \mathrm{~L}: 29.5 \mathrm{D}(\mathrm{T}$ $=30.5 \mathrm{~h}$ ). When a circadian oscillation becomes entrained to light cycles shorter than the oscillation's endogenous period ( $\tau \mathrm{h}$; about $24 \mathrm{~h}$ in this case) the light pulse must come to lie in the late subjective night to produce the phase advances necessary to correct $\tau$ to $\mathrm{T}$, whereas when the light cycle is longer than $\tau$ the light pulse must come to lie in the early subjective night to produce the phase delays required to make such a correction. In this experiment, therefore, simply changing the period of the light cycle results in the illumination of radically different circadian phases. In all experiments of this type, whenever $\varphi_{i}$ (at CT $21.5 \mathrm{~h}$ ) was computed to fall in the light, non-diapause ('long day') development was observed, whereas when $\varphi_{i}$ fell in the dark, diapause supervened. Results were therefore fully consistent with external coincidence for photoperiodic induction in $S$. argyrostoma and strong evidence for the circadian basis of photoperiodic time measurement in that species.

In the natural environment the photoperiodic mechanism in $S$. argyrostoma ensures that diapause is induced well before the onset of winter. In late summer, whilst night lengths are still short, the photoinducible phase $\left(\varphi_{\mathrm{i}}\right)$ is still illuminated by dawn light, leading to continued nondiapause development. As nights lengthen with the approach of autumn, $\varphi_{i}$ begins to fall in the dark: this occurs as the critical nightlength is passed. At this point the photoperiodic counter begins to accumulate the effects of abovecritical night lengths leading to a shut-down of PTTH secretion from the pupal brain, provided that a sufficient number of long-night cycles have been experienced before the larvae enter the soil to form puparia. The shut-down of PTTH secretion then leads to a low titre of ecdysteroids in the pupal instar and diapause ensues (Richard et al., 1987). To explain latitudinal effects on critical nightlength in $S$. similis, Yamaguchi \& Goto (2019) showed that the phase 'position' of $\varphi_{i}$ varies with latitude of origin, occurring earlier in the night with shorter critical nights (CNLs) of more northerly strains and later in the night with longer CNLs of more southerly strains. These data add further support to the external coincidence model being a valid photoperiodic model.

In a cybernetic or control systems computer model of the external coincidence photoperiodic clock in $S$. argyrostoma (Lewis \& Saunders, 1987; Saunders \& Lewis, $1987 \mathrm{a}, \mathrm{b})$, the photoperiodic oscillation was seen to be slowly dampening in constant darkness (DD) (see below) but when exposed to a train of light pulses during the larval sensitive period was 'boosted' above a threshold to give the diapause-inducing or nondiapause-inducing effects as outlined above. The number of such interactions were then accumulated by a 'counter' mechanism during the sensitive period. As with diapause induction in N. vitripennis, an interaction between a temperature-compensated photoperiodic counter and temperature-dependent larval development results in a higher incidence of pupal diapause at lower temperatures (Saunders, 1971, 1992).

\section{The role of circadian rhythmicity and clock genes in insect photoperiodism}

The whole-animal experiments described above strongly suggested that the circadian system was intimately involved, perhaps causally so, in photoperiodic time measurement in accordance with predictions arising from Bünning's hypothesis (1936). However, these experiments were conducted before the genetic basis of circadian rhythmicity in D. melanogaster was elucidated, before molecular techniques developed for Drosophila were extended to non-model species, or techniques for gene silencing introduced.

Gene silencing (RNA interference) techniques to knock down recognised circadian 'clock' genes have now been applied to several species with an initial expectation that such silencing might indicate a crucial role for clock genes in photoperiodic timing. These investigations include important studies by Pavelka et al. (2003), Sakamoto et al. (2009), Ikeno et al. (2010), Omura et al. (2016) and Meuti et al. (2015), reviewed in detail elsewhere (Saunders, 2020). Knock down of period in N. vitripennis by Mukai \& Goto (2016) has also indicated its importance in that species.

Emerson et al. (2009) pointed out that a circadian 'clock' (like that described for D. melanogaster; Hall, 2003; Hardin, 2005) comprises an interacting group of genes and proteins acting together as a functional unit or 'module'. Since the photoperiodic clock is probably also such a module it would also have to act in its entirety; therefore experiments based on knock down of single genes cannot differentiate between the action of a complete photoperiodic mechanism and simple gene pleiotropy. However, gene silencing studies using $R$. pedestris (Ikeno et al., 2010) and $C$. pipiens (Meuti et al., 2015) have compared results of several gene knock downs with observed circadian effects and go some way to satisfying this objection.

The alternating peaks and troughs of diapause incidence revealed by the Nanda-Hamner $(\mathrm{NH})$ experiment have been interpreted on numerous occasions as an expression of circadian rhythmicity in the photoperiodic clock itself, for example in S. argyrostoma (Saunders, 1973) and $N$. vitripennis (Saunders, 1974; see above). In the pitcher plant mosquito Wyeomyia smithii, however, Bradshaw et al. $(2003,2006,2012)$ showed that variation in the critical photoperiod (the most characteristic feature of photoperiodic induction) was not correlated with period of the NH rhythm. This study followed an earlier observation 
on diapause induction in the spider mite Tetranychus urticae by Vaz Nunes et al. (1990). Based on 10 geographical strains of the mite from Thessaloniki $\left(40.5^{\circ} \mathrm{N}\right)$ to $\mathrm{St}$ Petersburg $\left(60^{\circ} \mathrm{N}\right)$, results demonstrated a strong negative correlation between critical nightlength (CNL) and latitude for sea-level populations $(\mathrm{r}=-0.990)$, but only a weak positive correlation $(\mathrm{r}=0.544)$ between $\mathrm{CNL}$ and interpeak intervals in $\mathrm{NH}$ experiments, taken as an estimate of circadian period. Similar results were indicated in earlier studies using comparisons between CDL and period of the eclosion rhythm in Drosophila auraria (Pittendrigh et al., 1984) and D. littoralis (Lankinen, 1986).

Lankinen \& Forsman (2006), working with D. littoralis, applied antagonistic selection against the correlation between CDL and circadian period of the eclosion rhythm to test for genetic dependence or independence of the two traits. Using a northern strain $\left(65^{\circ} \mathrm{N}\right)$ showing a long CDL of $19.9 \mathrm{~h}$ and a short period of $18.8 \mathrm{~h}$, and a southern strain $\left(42^{\circ} \mathrm{N}\right)$ with a short CDL of $12.4 \mathrm{~h}$ and a long period of 22.8 $\mathrm{h}$, they subjected flies to 54 generations of such selection, resulting in a novel strain with 'southern' diapause characteristics but 'northern' characteristics of eclosion rhythmicity. A complete separation of these two traits was thus achieved. A similar approach was followed by Bradshaw et al. (2012) using antagonistic selection between CDL and $\mathrm{NH}$ interpeak intervals in $W$. smithii. After 10 generations of antagonistic selection, significant divergence of these traits was also achieved. The authors concluded that it was difficult to argue from such results that circadian rhythmicity formed the basis of photoperiodic time measurement and, therefore, that Bünning's hypothesis was not a valid explanation for this phenomenon. There is, however, an alternative explanation, one based on known features of insect circadian rhythms, which suggests the opposite.

The concept of a multioscillator circadian system has been supported by a large body of evidence since internal desynchronisation ('rhythm splitting') was first recorded by Pittendrigh (1960). It is now clear that circadian rhythmicity is essentially a cellular phenomenon and the insect circadian system resembles a multicellular, multioscillator 'clock-shop', clock-like properties being evident in a very wide range of tissues and organs (Plautz et al., 1997; Giebultowicz, 2001; Morioka et al., 2012; Ito \& Tomioka, 2016). For 'central' rather than peripheral functions, however, neurons in the central nervous system comprise the cellular clocks, regulating such phenomena as moulting, pupation, eclosion, locomotor activity - and photoperiodism. Truman (1972) recognised two such types of clock in insects: Type 1 controlling rhythms of egg hatch, moulting, eclosion (and photoperiodism) which had endocrine outputs, and showed a tendency to dampen and eventually become arrhythmic in continuous light, and Type 2 clocks controlling rhythms of locomotor activity which had a neural output, and persisted in continuous light of quite high intensity. Even in the same species, different clocks were apparent, Engelmann \& Mack (1978) showing that rhythms of adult activity and eclosion in D. pseudoobscura showed differences in their responses to light cycles, as re- vealed by phase response curves, as well as differences in output pathways to their respective rhythms. Rhythm splitting of activity rhythms is also frequent in insects (Christensen \& Lewis, 1982; Hong \& Saunders, 1982). In some species, activity is naturally bimodal, with 'morning' and 'evening' peaks in D. melanogaster (Hamblen-Coyle et al., 1992; Wheeler et al., 1993), the two peaks being controlled by separate groups of neurons in the brain (Grima et al., 2004).

There is, therefore, ample evidence to suggest that separate circadian oscillators occur in a variety of neurons, each showing differences in clock-related parameters such as sensitivity to light ('subjective light intensity'), PRC shape, period, phase relationship and nature of the output pathway, neural or endocrine. The antagonistic selection experiments performed by Lankinen \& Forsman (2006) on D. littoralis, and Bradshaw et al. (2012) on W. smithii certainly separated photoperiodic regulation from overtly rhythmic components - but do not show that photoperiodism is governed by a non-circadian mechanism. Together with results from whole-animal experiments reviewed above, a circadian-based photoperiodic timer remains the most appropriate explanation for this phenomenon.

\section{The photoperiodic mechanism is a dampening circadian oscillator}

Early attempts to characterise time measurement in insect photoperiodism resulted in a dichotomy of opinion that still resonates today. On the one hand Lees (1953, 1965, 1973), working with spider mites and later with aphids, advocated nightlength measurement by a timer that resembled an hourglass. On the other hand, Pittendrigh (1966) and Pittendrigh \& Minis (1964) supported Bünning's $(1936,1960)$ suggestion that photoperiodic time measurement was a function of the circadian system. The essential difference between the two models was that hourglass timing occurred just once (in each $24 \mathrm{~h}$ cycle), whereas the latter involved repetitive measurements of 'nightlength' at circadian intervals in protracted periods of darkness, as revealed, for example, in Nanda-Hamner experiments. Bünning (1969) suggested that hourglass-like timing was the result of rapid dampening of an oscillatory mechanism; evidence in favour of this proposition is now considered.

Despite the apparent differences between hourglasslike and circadian timing the two models also present many similarities. Comparing the aphid Megoura viciae and Sarcophaga spp, time measurement in both begins at light-off (Lees, 1973; Saunders, 1975b), and night interruption experiments then produce two points of short night (diapause averting) effect, one early (point A) and another late in the night (point B) (Lees, 1965; Saunders, 1975b). Action spectrum studies in M. viciae (Lees, 1973) and in S. similis (Goto \& Numata, 2009) also showed maximum sensitivity to blue-green light at point A, but a broader peak extending into longer wavelengths at point B. Moreover, in an experiment first devised for $M$. viciae using night interruptions in non-24 h cycles and later applied to $S$. argyrostoma (Saunders, 1979a) it was shown that the short-night (nondiapause inducing) effects of light falling in point $\mathrm{A}$ 
could be reversed by a following long night, whereas shortnight effects of light falling on point $\mathrm{B}$ were irreversible. This experiment, therefore, identified point $\mathrm{B}$ - late in the night in both species - as a photoinducible phase $\left(\varphi_{\mathrm{i}}\right)$ of an external coincidence type of photoperiodic timer. Further evidence for the involvement of circadian rhythmicity in aphid photoperiodism was provided by Hardie (1987) who demonstrated 'positive' responses of Aphis fabae in Nanda-Hamner photocycles, and by Vaz Nunes \& Hardie (1993) who showed repetitive time measurement in $M . v i-$ ciae when these aphids were exposed to extended nights. Mid-latitude insects other than aphids also presented evidence for oscillator dampening in their photoperiodic timers, declining amplitude of high diapause peaks in $\mathrm{NH}$ experiments occurring in S. argyrostoma and Calliphora vicina with an increase in cycle duration (Saunders \& Lewis, 1988), and Reznik \& Voinovich (2019) have provided further evidence for a rapidly dampening oscillator in the egg parasitoid Trichogramma telengai.

Oscillator dampening also seems to become increasingly prevalent in more northerly latitudes. The first indication of this was provided by Thiele (1977) who showed 'positive' resonance effects (multiple peaks of high diapause incidence in $\mathrm{NH}$ experiments) in a strain of the beetle Pterostichus nigrita in Germany $\left(51^{\circ} \mathrm{N}\right)$ but 'negative' hourglass-like responses in a strain from Swedish Lapland $\left(64\right.$ to $\left.66^{\circ} \mathrm{N}\right)$. Hourglass-like $\mathrm{NH}$ responses have now been recorded in several species of Drosophila in Finland including D. ezoana (Vaze \& Helfrich-Förster, 2016) and D. montana (Kauranan et al., 2019; Tyukmaeva et al., 2020).

Why should aphids and insects at high latitude present photoperiodic clocks resembling hourglasses, whereas other species appear to possess clocks with clear circadian properties? For aphids (and perhaps also spider mites), with rapid development, few (or even one) long nights are sufficient, and in the absence of strong selective advantage for repetitive nightlength measurement this trait becomes deselected. At high latitudes, twilights at dawn and dusk become protracted and less precise. Nightlength at high latitudes also changes more rapidly in the autumn than it does further south and thus becomes a less reliable signal of seasonal change. In such conditions a highly damped hourglass-like timer may synchronise more easily to rapidly lengthening autumnal nights than a more robustly circadian mechanism. Once again, if relaxed selection (e.g. Aalberg Haugen \& Gotthard, 2015) for repetitive nightlength measurement occurs, photoperiodic time measurement based on continued rhythmicity might then decline.

\section{Seasonality in polar regions}

In the polar regions, seasons are even more marked with long periods during summer in constant light, winter in darkness for months on end, rapid changes in photoperiod during seasonal changes, and a very short 'growing season'. Above the Arctic circle, the insect fauna is severely impoverished (Downes, 1966) and most insects appear to overwinter in a state of cold hardiness, sometimes freeze tolerant, and not under photoperiodic control but as a direct response to the prevailing cold.
Whereas mid-latitude insects may be multivoltine or bivoltine and become univoltine further north, many Arctic insects pass through an indefinite number of winters in succession with a dormant stage in different instars. The moth Gynaephora groenlandica lives in the high Arctic of northern Canada and Greenland at latitudes above $70^{\circ} \mathrm{N}$. It has a greatly extended life cycle up to 7 years, each winter spent in dormancy with moulting occurring every spring (Morewood \& Ring, 1998). In its dormant state it can withstand freezing at temperatures as low as $-70^{\circ} \mathrm{C}$. The larvae are active during the short Arctic summer under $24 \mathrm{~h}$ of light per day, but by late June or early July start preparation for their annual entry into dormancy. Since they are exposed to constant light during this period, and dormancy occurs annually in different instars, dormancy in G. groenlandica does not conform to diapause sensu stricto but is probably a response to low temperature, leading to cold hardening and the synthesis of cryoprotective compounds.

Seasonal development of insects in the High Arctic is mirrored in the Antarctic, where the flightless midge Belgica antarctica spends its two-year life cycle overwintering in any of its four larval instars. B. antarctica is the only insect endemic to the Antarctic continent (Convey \& Block, 1996), occurring along the western coast of the Antarctic Peninsula $\left(61\right.$ to $\left.68^{\circ} \mathrm{S}\right)$ and on nearby islands. Larvae spend the winter encased in ice, pupate in the spring after snow melt and the wingless adults are briefly active during the short Antarctic summer. At these latitudes daylength at mid-summer is about $21 \mathrm{~h}$, but the Sun is never far below the horizon; consequently 'twilight' illumination is extensive. Soon after the summer solstice larvae begin preparation for upcoming winter dormancy, but they are always exposed to light of some intensity over the $24 \mathrm{~h}$ period. Under field conditions the larvae are most active during the warmest part of the day but, in the laboratory, activity becomes arrhythmic in constant darkness with no sign of overt circadian activity (Kobelkova et al., 2015). Furthermore, these authors showed that the canonical circadian clock genes period, timeless, Clock and vrille showed no cycling of expression, and they concluded that circadian function of these genes had been rendered inactive. Since circadian clock genes are thought also to be involved in the photoperiodic diapause induction (see above), dormancy in $B$. antarctica is likely to be a direct response to changing temperature rather than to the unreliable light cycles. Seasonal synchrony of $B$. antarctica in southern polar regions therefore resembles that of insects in the Arctic in that photoperiod ceases to be an environmental factor inducing diapause.

\section{OVERVIEW}

In mid-latitude insects, both diapause and low temperature-induced quiescence provide mechanisms for insects to become dormant and to avoid many of the deleterious effects of winter. Diapause, however, is induced by photoperiod (or other 'token' stimuli) acting well in advance of the impending dormancy, whereas quiescence is a more immediate response to cold (or low humidity) that 
is promptly terminated by return to favourable conditions. Diapause occurs at species-specific stages of development - egg (embryonic), larva, pupa or adult - but with little evidence of phylogenetic relationships. Although many Drosophila spp., for example, overwinter in a reproductive diapause, larval diapause has been recorded in $D$. deflexa (Basden, 1954) and pupal diapause in D. alpina (Lumme, 1978). This suggests that diapause has evolved on numerous occasions, giving rise to extensive variations in physiology and behaviour. Despite some contrary opinion, there is increasing evidence that photoperiodic time measurement is a function of the circadian system, and the photoperiodic oscillator(s) measure nightlength rather than daylength. The oscillatory system also dampens in extended periods of darkness, rapid dampening giving rise to nightlength hourglass-like timers in aphids and in insects living at higher latitudes. Close to the equator, where seasonal changes in photoperiod are slight or absent, and in polar regions where they are too extreme, photoperiodic regulation of diapause becomes problematic and, in many cases, dormancy in these areas more closely resembles quiescence. Drosophila melanogaster, which is of tropical origin and extended its geographical distribution to more northerly latitudes, seems not to have evolved a photoperiodic diapause, female flies surviving the winter as commensals in a state of quiescence. Antagonistic selection experiments have succeeded in separating photoperiodic induction from aspects of overt circadian rhythmicity prompting the suggestion that the former is not regulated by the circadian system. However, the view that photoperiodic induction has a circadian basis is considered a more parsimonious explanation for the phenomenon than proposing an entirely new and unknown mechanism.

\section{REFERENCES}

Aalberg Haugen I.M. \& GotThard K. 2015: Diapause induction and relaxed selection on alternative developmental pathways in a butterfly. - J. Anim. Ecol. 84: 464-472.

ANDO Y. 1991: Photoperiodic control of adult diapause in a subtropical katydid, Euconocephalus pallidus Redtenbacher (Orthoptera: Tettigoniidae). — Appl. Entomol. Zool. 26: 347-355.

Anduaga A.M., Nagy D., Costa R. \& Kyriacou C.P. 2018: Diapause in Drosophila melanogaster - Photoperiodicity, cold tolerance and metabolites. - J. Insect Physiol. 105: 46-53.

Ankersmit G.W. \& AdKIsson P.L. 1967: Photoperiodic responses of certain geographical strains of Pectinophora gossypiella (Lepidoptera). - J. Insect Physiol. 13: 553-564.

Basden E.B. 1954: Diapause in Drosophila (Diptera: Drosophilidae). - Proc. R. Entomol. Soc. Lond. (A) 29: 114-118.

BEACH R.F. 1978: The required day number and timely induction of diapause in geographic strains of the mosquito, Aedes atropalpus. - J. Insect Physiol. 24: 449-455.

Bell C.H., Cox P.D., Allen L.P., Pearson J. \& Beirne M.A. 1983: Diapause in twenty populations of Ephestia cautella (Walker) (Lepidoptera: Pyralidae) from different parts of the world. - J. Stor. Prod. Res. 19: 117-123.

BLAKE G.M. 1958: Diapause and the regulation of development in Anthrenus verbasci (L.) (Col., Dermestidae). - Bull. Entomol. Res. 49: 751-775.
BlaKe G.M. 1959: Control of diapause by an 'internal clock' in Anthrenus verbasci (L.) (Col., Dermestidae). - Nature 183: 126-127.

Bouletreau-Merle J. \& Fouillet P. 2002: How to overwinter and be a founder: egg-retention phenotypes and mating status in Drosophila melanogaster. - Evol. Ecol. 16: 309-332.

BRADSHAW W.E. 1976: Geography of photoperiodic response in a diapausing mosquito. - Nature 262: 384-386.

Bradshaw W.E., Quebodeaux M.C. \& Holzapfel C.M. 2003: Circadian rhythmicity and photoperiodism in the pitcher-plant mosquito: adaptive response to the photic environment or correlated response to the seasonal environment? - Am. Nat. 161: 735-748.

Bradshaw W.E., Holzapfel C.M. \& Mathias D. 2006: Circadian rhythmicity and photoperiodism in the pitcher-plant mosquito: can the seasonal timer evolve independently of the circadian clock? - Am. Nat. 167: 601-605.

Bradshaw W.E., Emerson K.J. \& Holzapfel C.M. 2012: Genetic correlations and the evolution of photoperiodic time measurement within a local population of the pitcher-plant mosquito, Wyeomyia smithii. — Heredity 108: 473-479.

BüNnING E. 1936: Die endogene Tagesrhythmik als Grundlage der Photoperiodischen Reaktion. - Ber. Dt. Bot. Ges. 54: 590-607.

BüNNING E. 1960: Circadian rhythms and time measurement in photoperiodism. - Cold Spring Harb. Symp. Quant. Biol. 25: 249-256.

BüNnING E. 1969: Common features of photoperiodism in plants and animals. - Photochem. Photobiol. 9: 219-222.

Christensen N.D. \& Lewis R.D. 1982: The circadian locomotor rhythm of Hemideina thoracica (Orthoptera: Stenopelmatidae): the circadian clock as a population of interacting oscillators. - Physiol. Entomol. 7: 1-13.

Convey P. \& Block W. 1996: Antarctic Diptera: Ecology, physiology and distribution. - Eur. J. Entomol. 93: 1-13.

DANILEVSKII A.S. 1957: [Photoperiodism as a factor of formation of geographic races in insects.] — Entomol. Obozr. 36: 5-27 [in Russian].

Danilevskit A.S. 1965: Photoperiodism and the Seasonal Development of Insects. $1^{\text {st }}$ English ed. Oliver \& Boyd, Edinburgh and London, $283 \mathrm{pp}$.

De Loof A., van Loon J. \& Vanderroost C. 1979: Influence of ecdysterone, precocene and compounds with juvenile hormone activity on induction, termination and maintenance of diapause in the parasitoid wasp, Nasonia vitripennis. - Physiol. Entomol. 4: 319-328.

DenLINGER D.L. 1971: Embryonic determination of pupal diapause in the flesh fly Sarcophaga crassipalpis. - J. Insect Physiol. 17: 1815-1822.

DenLINGER D.L. 1972a: Induction and termination of pupal diapause in Sarcophaga (Diptera: Sarcophagidae). - Biol. Bull. 142: 11-24.

Denlinger D.L. 1972b: Seasonal phenology of diapause in the flesh fly Sarcophaga bullata. - Ann. Entomol. Soc. Am. 65: 410-414.

Denlinger D.L. 1978: The developmental response of flesh flies (Diptera: Sarcophagidae) to tropical seasons. - Oecologia (Berl.) 35: 105-107.

Denlinger D.L. 1979: Pupal diapause in tropical flesh flies: environmental and endocrine regulation, metabolic rate and genetic selection. - Biol. Bull. 156: 31-46.

Denlinger D.L. 1985: Hormonal control of diapause. In Kerkut G.A. \& Gilbert L.I. (eds): Comprehensive Insect Physiology, Biochemistry and Pharmacology. Vol. 8. Pergamon Press, Oxford, pp. 353-412. 
DenLinger D.L. 1986: Dormancy in tropical insects. - Annu. Rev. Entomol. 31: 239-264.

Downes J.A. 1965: Adaptations of insects in the Arctic. - Annu. Rev. Entomol. 10: 257-274

Eertmoed G. 1978: Embryonic diapause in the psocid, Peripsocus quadrifasciatus: photoperiod, temperature, ontogeny and geographical variation. - Physiol. Entomol. 3: 197-206.

Emerson K.J., Bradshaw W.E. \& Holzapfel C.M. 2009: Complications of complexity: integrating environmental, genetic and hormonal control of insect diapause. - TIGS 25: 217-225.

Engelmann W. \& Mack J. 1978: Different oscillators control the circadian rhythm of eclosion and activity in Drosophila. - J. Comp. Physiol. (A) 127: 229-237.

Giebultowicz J.M. 2001: Peripheral clocks and their role in circadian timing: insights from insects. - Phil. Trans. R. Soc. Lond. (B) 356: 1791-1799.

Goto S.G. \& Numata H. 2009: Possible involvement of distinct photoreceptors in the photoperiodic induction of diapause in the flesh fly Sarcophaga similis. — J. Insect Physiol. 55: 401407.

Grima B., Chelot E., Xia R. \& Rouyer F. 2004: Morning and evening peaks of activity rely on different clock neurons of the Drosophila brain. - Nature 431: 869-873.

Hackett D.S. \& Gatehouse A.G. 1982: Diapause in Heliothis armigera (Hübner) and H. fletcheri (Hardwick) (Lepidoptera: Noctuidae) in the Sudan Gezira. - Bull. Entomol. Res. 72 409-422.

HALL J.C. 2003: Genetics and molecular biology of rhythms in Drosophila and other insects. - Adv. Genet. 48: 1-280.

Hamblen-Coyle M.J., Wheeler D.A., Rutila J.E., Rosbash M. \& HaLl J.C. 1992: Behavior of period-altered circadian rhythm mutants of Drosophila in light-dark cycles (Diptera: Drosophilidae). - J. Insect Behav. 5: 417-446.

HARDIE J. 1987: The photoperiodic control of wing development in the black bean aphid, Aphis fabae. - J. Insect Physiol. 33: 543-549.

HaRdin P.E. 2005: The circadian timekeeping system of Drosophila. - Curr. Biol. 15: R714-722.

HenNeGUY L.F. 1904: Les Insectes. Morphologie, reproduction, embryogénie. Masson, Paris, xviii +804 pp.

Henrich V.C. \& DenLinger D.L. 1982: A maternal effect that eliminates pupal diapause in progeny of the flesh fly, Sarcophaga bullata. - J. Insect Physiol. 28: 881-884.

Hodek I. 1968: Diapause in females of Pyrrhocoris apterus L. (Heteroptera). - Acta Entomol. Bohemoslov. 65: 422-435.

Hodek I. 1971: Termination of adult diapause in Pyrrhocoris apterus (Heteroptera: Pyrrhocoridae) in the field. - Entomol. Exp. Appl. 14: 212-222.

Hong S.-F. \& SAUNDERS D.S. 1998: Internal desynchronisation in blow fly (Calliphora vicina) locomotor activity rhythms: evidence for a complex circadian pacemaker. - Biol. Rhythm Res. 29: 387-396.

Horwath K.L. \& Duman J.G. 1982: Involvement of the circadian system in photoperiodic regulation of insect antifreeze proteins. - J. Exp. Zool. 219: 269-270.

Horwath K.L. \& Duman J.G. 1983: Photoperiodic and thermal regulation of antifreeze protein levels in the beetle Dendroides canadensis. - J. Insect Physiol. 29: 907-917.

Hut R.A., Paolucci S., Dor R., Kyriacou C.P. \& DaAn S. 2013. Latitudinal clines: an evolutionary view on biological rhythms. _ Proc. R. Soc. (B) 280: 20130433, 9 pp.

Ikeno T., Tanaka H., Numata H. \& Goto S.G. 2010: Photoperiodic diapause under the control of circadian clock genes in an insect. - BMC Biol. 8: 116, 9 pp.
Iто C. \& Томіока K. 2016: Heterogeneity of the peripheral circadian system in Drosophila melanogaster: a review. - Front. Physiol. 7: 8, $7 \mathrm{pp}$.

IzQUIERDO J.I. 1991: How does Drosophila melanogaster overwinter? - Entomol. Exp. Appl. 59: 51-58.

Kauranen H., Kinnunen J., Hiillos A.-L., Lankinen P., Hopkins D., Wiberg R., Ritchie M.G. \& HoikKala A. 2019: Selection for reproduction under short photoperiods changes diapauseassociated traits and induces widespread genomic divergence. - J. Exp. Biol. 222: 205831, 14 pp.

Kenny N.A.P., Richard D.S., Bradley H.K. \& Saunders D.S. 1992: Photoperiodic sensitivity and diapause induction during ovarian, embryonic and larval development of the flesh fly, Sarcophaga argyrostoma. - J. Biosci. 17: 241-251.

KiKaKaWA S. \& Chippendale G.M. 1983: Seasonal adaptations of populations of the southwestern corn borer, Diatraea grandiosella, from tropical and temperate regions. $-J$. Insect Physiol. 29: 561-567.

Kishino K. 1974: Ecological studies on the local characteristics of the seasonal development in the rice stem borer Chilo suppressalis Walker. - Bull. Tohoku Agr. Exp. Sta. 47: 13-114 [in Japanese].

Kobelkova A., Goto S.G., Peyton J.T., Ikeno T., Lee R.E. Jr. \& DenLINGER D.L. 2015: Continuous activity and no cycling of clock genes in the Antarctic midge during the polar summer. - J. Insect Physiol. 81: 90-96.

KošTÁL V. \& HoDEK I. 1997: Photoperiodism and control of summer diapause in the Mediterranean tiger moth Cymbalophora pudica. - J. Insect Physiol. 43: 767-777.

LANKINEN P. 1986: Geographical variation in circadian eclosion rhythms and photoperiodic adult diapause in Drosophila littoralis. - J. Comp. Physiol. (A) 159: 123-142.

LANKInen P. \& Forsman P. 2006: Independence of genetic geographical variation between photoperiodic diapause, circadian eclosion rhythm, and the Thr-Gly repeat region of the period gene in Drosophila littoralis. - J. Biol. Rhythms 21: 3-12.

LeE R.E. JR. \& DeNLINGER D.L. (eds) 1991: Insects at Low Temperature. Chapman and Hall, New York and London, 513 pp.

LeEs A.D. 1953: The significance of the light and dark phases in the photoperiodic control of diapause in Metatetranychus ulmi Koch. - Ann. Appl. Biol. 40: 487-497.

Lees A.D. 1955: The Physiology of Diapause in Arthropods. Cambridge Monographs in Experimental Biology, No. 4. Cambridge University Press, $151 \mathrm{pp}$.

LEES A.D. 1960: The role of photoperiod and temperature in the determination of parthenogenetic and sexual forms in the aphid Megoura viciae Buckton - II. The operation of the interval timer' in young clones. - J. Insect Physiol. 4: 154-175.

LEES A.D. 1965: Is there a circadian component in the Megoura photoperiodic clock? In Aschoff J. (ed.): Circadian Clocks. North-Holland Publishing, Amsterdam, pp. 351-356.

LEES A.D. 1973: Photoperiodic time measurement in the aphid Megoura viciae. - J. Insect Physiol. 19: 2279-2316.

Lemeunier F., David J.R., Tsacas L. \& Ashburner M. 1986: The melanogaster species group. In Ashburner M. \& Thompson J.N. Jr. (eds): The Genetics and Biology of Drosophila. Vol. $3 e$. Academic Press, New York, pp. 148-256.

LEWIS R.D. \& SAUNDERS D.S. 1987: A damped circadian oscillator model of an insect photoperiodic clock. I. Description of the model based on a feedback control system. $-J$. Theor. Biol. 128: $47-59$.

Lumme J. 1978: Phenology and photoperiodic diapause in northern populations of Drosophila. In Dingle H. (ed): Evolution of Insect Migration and Diapause. Springer, Berlin, pp. 145-170. 
MANSINGH A. 1971: Physiological classification of dormancies in insects. - Can. Entomol. 103: 983-1009.

MASAKI S. 1956: The local variation in the diapause pattern of the cabbage moth Barathra brassicae Linné, with special reference to the aestival diapause (Lepidoptera: Noctuidae). - Bull. Fac. Agric. Mie Univ. 13: 29-46.

MasaKi S. 1980: Summer diapause. - Annu. Rev. Entomol. 25: $1-25$.

MASAKI S. 2002: Ecophysiological consequences of variability in diapause intensity. - Eur. J. Entomol. 99: 143-154.

Masaki S., Shirado I. \& Nagase A. 1987: Tropical, subtropical and temperate life cycles in ground crickets. - Insect Sci. Appl. 8: 475-481.

Matsuda N., Kanbe T., Aкimoto S.I. \& Numata H. 2017: Transgenerational seasonal timer for suppression of sexual morph production in the pea aphid, Acyrthosiphon pisum. - J. Insect Physiol. 101: 1-6.

McLeod D.G.R. \& BECK S.D. 1963: Photoperiodic termination of diapause in an insect. - Biol. Bull. 124: 84-96.

McWatters H.G. \& Saunders D.S. 1996: The influence of each parent and geographic origin on larval diapause in the blow fly, Calliphora vicina. - J. Insect Physiol. 42: 721-726.

MCWatters H.G. \& SAUNDERS D.S. 1998: Maternal temperature has different effects on the photoperiodic response and duration of larval diapause in the blow fly (Calliphora vicina) strains collected at two latitudes. - Physiol. Entomol. 23: 369-375.

Menegazzi P., Vanin S., Yoshit T., Rieger D., Hermann C., Dusik V., Kyriacou C.P., Helfrich-Förster C. \& Costa R. 2013: Drosophila clock neurons under natural conditions. - J. Biol. Rhythms 28: 3-14.

Meuti M., Stone M., Ikeno T. \& Denlinger D.L. 2015: Functional circadian clock genes are essential for the overwintering diapause of the northern house mosquito Culex pipiens. $-J$. Exp. Biol. 218: 412-422.

MINIS D.H. 1965: Parallel peculiarities in the entrainment of a circadian rhythm and photoperiodic induction in the pink boll worm (Pectinophora gossypiella). In Aschoff J. (ed.): Circadian Clocks. North-Holland Publishing, Amsterdam, pp. 333343.

Mitrovski P. \& Hoffmann A.A. 2001: Postponed reproduction as an adaptation to winter conditions in Drosophila melanogaster: evidence for clinal variation under semi-natural conditions. Proc. R. Soc. Lond. (B) 268: 2163-2168.

Morewood W.D. \& Ring R.A. 1998: Revision of the life history of the High Arctic moth Gynaephora groenlandica (Wocke) (Lepidoptera: Lymantriidae). - Can. J. Zool. 76: 1371-1381.

Morioka E., Matsumoto A. \& Ikeda M. 2012: Neuronal influence on peripheral clocks in pupal Drosophila prothoracic glands. - Nat. Commun. 3: 909, 11 pp.

Mukai A. \& Goto S.G. 2016: The clock gene period is essential for the photoperiodic response in the jewel wasp Nasonia vitripennis (Hymenoptera: Pteromalidae). - Appl. Entomol. Zool. 51: 185-194.

Nagy D., Andreatta G., Basitanello S., Anduaga A.M., MazzotTa G., Kyriacou C.P. \& Costa R. 2018: A semi-natural approach for studying seasonal diapause in Drosophila melanogaster reveals robust photoperiodicity. - J. Biol. Rhythms 33: $117-125$.

NANDA K.K. \& Hamner K.C. 1958: Studies on the nature of the endogenous rhythm affecting photoperiodic response of Biloxi soybean. - Bot. Gaz. 120: 14-25.

Nelson R.J., Denlinger D.L. \& Somers D.E. (eds) 2010: Photoperiodism: The Biological Calendar. Oxford University Press, Oxford, $581 \mathrm{pp}$.
Nisimura T. \& Numata H. 2001: Endogenous timing mechanism controlling the circannual pupation rhythm of the varied carpet beetle Anthrenus verbasci. - J. Comp. Physiol. (A) 187: 433-440.

NorRIS M.J. 1962: Diapause induced by photoperiod in a tropical locust, Nomadacris septemfasciata (Serv.). - Ann. Appl. Biol. 50: $600-603$.

NoRRIS M.J. 1965: The influence of constant and changing photoperiods on imaginal diapause in the red locust (Nomadacris septemfasciata Serv.). - J. Insect Physiol. 11: 1105-1119.

Omura S., Numata H. \& Goto S.G. 2016: Circadian clock regulates photoperiodic responses governed by distinct output pathways in the bean bug, Riptortus pedestris. - Biol. Rhythm Res. 47: 937-945.

Orshan L. \& Pener M.P. 1979: Termination and reinduction of reproductive diapause by photoperiod and temperature in males of the grasshopper, Oedipoda miniata. - Physiol. Entomol. 4: 55-61.

PAARMAN W. 1970: Untersuchungen über die Jahresrhythmik von Laufkäfern (Coleoptera, Carabidae) in der Cyrenaika (Libyen, Nordafrika). - Oecologia 5: 325-333.

PaArman W. 1974: Der Einfluss von Temperatur und Lichtwechsel des Laufkäfers Broscus laevigatus Dej. (Col., Carab.) aus Nordafrika. - Oecologia 15: 87-92.

Paolucci S., van der Zande L. \& BeuKeboom L.W. 2013: Adaptive latitudinal cline of photoperiodic diapause induction in the parasitoid Nasonia vitripennis in Europe. - J. Evol. Biol. 26: 705-718.

PaVelka J., Shimada K. \& KoŠtál V. 2003: TIMELESS: a link between fly's circadian and photoperiodic clocks? - Eur. J. Entomol. 100: 255-265.

Pegoraro M., Zonato V., Tyler E.R., Fedele G., Kyriacou C.P. \& TAUBER E. 2017: Geographical analysis of diapause inducibility in European Drosophila melanogaster populations. - J. Insect Physiol. 98: 238-244.

PitTendRigh C.S. 1960: Circadian rhythms and the circadian organization of living systems. - Cold Spring Harb. Symp. Quant. Biol. 25: 159-184.

PITTENDRIGH C.S. 1966: The circadian oscillation in Drosophila pseudoobscura pupae: a model for the photoperiodic clock. Z. Pflanzenphysiol. 54: 275-307.

PITTENDRIGH C.S. 1972: Circadian surfaces and the diversity of possible roles of circadian organization in photoperiodic induction. - Proc. Nat. Acad. Sci. USA 69: 2734-2737.

PitTEnDRigh C.S. \& Minis D.H. 1964: The entrainment of circadian oscillations by light and their role as photoperiodic clocks. - Am. Nat. 98: 261-294.

Pittendrigh C.S., Elliott J. \& Takamura T. 1984: The circadian component in photoperiodic induction. In Porter R. \& Collins G.M. (eds): Photoperiodic Regulation of Insect and Molluscan Hormones. Ciba Foundation Symposium No. 104, Pitman, London, pp. 26-47.

Plautz J.D., Kaneko M., Hall J.C. \& Kay S.A. 1997: Independent photoreceptive circadian clocks throughout Drosophila. Science 278: 1632-1635.

REZNIK S.Y. \& VoINOVICH N.D. 2019: The photoperiodic response to single nights suggests a rapidly damping oscillator in Trichogramma telengai (Hymenoptera: Trichogrammatidae). - Can. Entomol. 151: 1-9.

Richard D.S., Warren J.T., SAunders D.S. \& Gilbert L.I. 1987: Haemolymph ecdysteroid titres in diapause and nondiapause destined larvae and pupae of Sarcophaga argyrostoma. - J. Insect Physiol. 33: 115-122.

RiedL B. \& Croft B.A. 1978: The effects of photoperiod and effective temperatures on the seasonal phenology of the cod- 
ling moth (Lepidoptera: Tortricidae). — Can. Entomol. 110 $455-470$.

Roberts D.B. 1985: Basic Drosophila care and techniques. In Roberts D.B. (ed.) Drosophila, a Practical Approach. IRL Press, Oxford, pp. 1-38.

Rockey S.J., Miller B.B. \& Denlinger D.L. 1989: A diapause maternal effect in the flesh fly, Sarcophaga bullata: transfer of information from mother to progeny. - J. Insect Physiol. 35: 553-558.

Rubin E.B., Shemesh Y., Cohen M., Elgavish S., Robertson H.M. \& BLOCH C. 2006: Molecular and phylogenetic analyses reveal mammalian-like clockwork in the honeybee (Apis mellifera) and shed new light on the molecular evolution of the circadian clock. - Genome Res. 16: 1352-1365.

SAKamoto T., Uryo O. \& TomioKa K. 2009: The clock gene period plays an essential role in photoperiodic control of nymphal development in the cricket Modicogryllus siamensis. - J. Biol. Rhythms 24: 379-390.

SAUNDERS D.S. 1965: Larval diapause induced by a maternallyoperating photoperiod. - Nature 206: 739-740.

SAUNDERS D.S. 1966: Larval diapause of maternal origin-11. The effect of photoperiod and temperature on Nasonia vitripennis. — J. Insect Physiol. 12: 569-581.

SAUNDERS D.S. 1967: Time measurement in insect photoperiodism: reversal of a photoperiodic effect by chilling. - Science 156: $1126-1127$.

SAUNDERS D.S. 1969: Diapause and photoperiodism in the parasitic wasp Nasonia vitripennis, with special reference to the nature of the photoperiodic clock. - Symp. Soc. Exp. Biol. 23: 301-329.

SAUNDERS D.S. 1971: The temperature-compensated photoperiodic clock 'programming' development and pupal diapause in the flesh-fly, Sarcophaga argyrostoma. - J. Insect Physiol. 17: 801-812.

SAUNDERS D.S. 1973: Thermoperiodic control of diapause in an insect: theory of internal coincidence. - Science 181: 358360 .

SAUNDERS D.S. 1974: Evidence for 'dawn' and 'dusk' oscillators in the Nasonia photoperiodic clock. - J. Insect Physiol. 20: $77-88$.

SAUNDERS D.S. 1975a: Spectral sensitivity and intensity thresholds in Nasonia photoperiodic clock. - Nature 253: 732-735.

SAUNDERS D.S. 1975b: 'Skeleton' photoperiods and the control of diapause and development in the flesh-fly, Sarcophaga argyrostoma. - J. Comp. Physiol. 97: 97-112.

SAUNDERS D.S. 1978: An experimental and theoretical analysis of photoperiodic induction in the flesh fly Sarcophaga argyrostoma. - J. Comp. Physiol. (A) 124: 75-95.

SAUNDERS D.S. 1979a: External coincidence and the photoinducible phase in the Sarcophaga photoperiodic clock. - J. Comp. Physiol. (A) 132: 179-189.

SAUNDERS D.S. 1979b: The circadian eclosion rhythm in Sarcophaga argyrostoma: delineation of the responsive period for entrainment. - Physiol. Entomol. 4: 263-274.

SAUNDERS D.S. 1981: Insect photoperiodism: the clock and the counter. - Physiol. Entomol. 6: 99-116.

SAUNDERS D.S. 1983: A diapause induction-termination asymmetry in the photoperiodic responses of the linden bug, Pyrrhocoris apterus, and an effect of near-critical photoperiods on development. - J. Insect Physiol. 29: 399-405.

SAUNDERS D.S. 1987: Maternal influence on the incidence and duration of larval diapause in Calliphora vicina. - Physiol. Entomol. 12: 331-338.

SAUNDERS D.S. 1990: The circadian basis of ovarian diapause regulation in Drosophila melanogaster: is the period gene caus- ally involved in photoperiodic time measurement? - J. Biol. Rhythms 5: 315-331.

SAUNDERS D.S. 1992: The photoperiodic clock and 'counter' in Sarcophaga argyrostoma: Experimental evidence consistent with 'external coincidence' in insect photoperiodism. $-J$. Comp. Physiol. (A) 170: 121-127.

SAUNDERS D.S. 2008: Photoperiodism in insects and other animals. In Bjorn L.O. (ed.): Photobiology: The Science of Life and Light. 2nd ed. Springer, New York, pp. 389-416.

SAUNDERS D.S. 2010: Photoperiodism in insects: migration and diapause responses. In Nelson R.J., Denlinger D.L. \& Somers D.E. (eds): Photoperiodism: The Biological Calendar. Oxford University Press, pp. 218-257.

SAunders D.S. 2020: Dormancy, diapause and the role of the circadian system in insect photoperiodism. - Annu. Rev. Entomol. 65: 19.1-19.17.

SAUNDERS D.S. \& HaYward S.A.L. 1998: Geographical and diapause-related cold tolerance in the blow fly, Calliphora vicina. - J. Insect Physiol. 44: 541-551.

SAunders D.S. \& Lewis R.D. 1987a: A damped circadian oscillator model of an insect photoperiodic clock. II. Simulations of the shapes of the photoperiodic response curves. $-J$. Theor. Biol. 128: 61-71.

SAUNDERS D.S. \& LewIS R.D. 1987b: A damped circadian oscillator model of an insect photoperiodic clock. III. Circadian and "hourglass" responses. - J. Theor. Biol. 128: 73-85.

SAunders D.S. \& Lewis R.D. 1988: The photoperiodic clock and counter mechanism in two species of flies: Evidence for damped circadian oscillators in time measurement. - J. Comp. Physiol. (A) 163: 365-371.

Saunders D.S., Henrich V.C. \& Gilbert L.I. 1989: Induction of diapause in Drosophila melanogaster: Photoperiodic regulation and the impact of arrhythmic clock mutations on time measurement. - Proc. Nat. Acad. Sci. USA 86: 3748-3752.

Saunders D.S., Richard D.S., Applebaum S.W., Ma M. \& GilBERT L.I. 1990: Photo-periodic diapause in Drosophila melanogaster involves a block to the juvenile hormone regulation of ovarian maturation. - Gen. Comp. Endocr. 79: 174-184.

Schmidt P.S., Matzkin L., Ippolito M. \& Eanes W.F. 2005: Geographic variation in diapause incidence, life-history traits, and climatic adaptation in Drosophila melanogaster. - Evolution 59: $1721-1732$.

Schneiderman H.A. \& Horwitz J. 1958: The induction and termination of facultative diapause in the chalcid wasps Mormoniella vitripennis (Walker) and Tritneptis klugii (Ratzeburg). —J. Exp. Biol. 35: 520-551.

Schurko A.M., Mazur D.J. \& Logsdon J.M. JR. 2010: Inventory and phylogenomic distribution of meiotic genes in Nasonia vitripennis and among diverse arthropods. - Insect Mol. Biol. 19: $165-180$.

SPITZER K. 1980: The life-cycle synchronization of Euprepia pudica (Lepidoptera, Arctiidae) to the Mediterranean climate. Acta Entomol. Bohemoslov. 77: 16-19.

Tanaka S., Denlinger D.L. \& Wolda H. 1987: Daylength and humidity as environmental cues for diapause termination in a tropical beetle. - Physiol. Entomol. 12: 213-224.

TanaKa S., Denlinger D.L. \& Wolda H. 1988: Seasonal changes in the photoperiodic response regulating diapause in a tropical beetle, Stenotarsus rotundus. - J. Insect Physiol. 34: 11351142.

TAuber M.J. \& TAuber C.A. 1972: Geographic variation in critical photoperiod and in diapause intensity of Chrysopa carnea (Neuroptera). - J. Insect Physiol. 18: 25-29.

Tauber M.J., Tauber C.A. \& Masaki S. 1986: Seasonal Adaptations of Insects. Oxford University Press, $411 \mathrm{pp}$. 
THIELE H.-U. 1977: Differences in measurement of daylength and photoperiodism in two stocks from sub-arctic and temperate climates in the beetle, Pterostichus nigrita. - Oecologia 30: 349-365.

Truman J.W. 1972: Circadian rhythms and physiology with special reference to neuroendocrine processes in insects. In $\mathrm{Bi}$ erhuizen J.F. (ed.): Circadian Rhythmicity. Proceedings of the International Symposium on Circadian Rhythmicity, Wageningen, the Netherlands, 26-29 April 1971. Centre for Agricultural Publishing and Documentation, Wageningen, pp. 111-135.

Tyshchenko V.P. 1966: Two-oscillatory model of the physiological mechanism of insect photoperiodic reaction. $-\mathrm{Zh}$. Obshch. Biol. 27: 209-222 [in Russian].

Tyukmaeva V., Lankinen P., Kinnunen J., Kauranen H. \& HoikKALA A. 2020: Latitudinal clines in the timing and temperaturesensitivity of photoperiodic reproductive diapause in Drosophila montana. - Ecography 43: 1-11.

VAZ Nunes M. \& Hardie J. 1993: Circadian rhythmicity is involved in photoperiodic time measurement in the aphid Megoura viciae. - Experientia 49: 711-713.

Vaz Nunes M., Koveos D.S. \& Veerman A. 1990: Geographical variation in photoperiodic induction of diapause in the spider mite (Tetranychus urticae): A causal relation between critical night length and circadian period? - J. Biol. Rhythms 5: $47-57$.
VAze K.M. \& Helfrich-Förster C. 2016: Drosophila ezoana uses an hour-glass or highly damped circadian clock for measuring night length and inducing diapause. - Physiol. Entomol. 41: $378-389$.

Vesala L. \& HoikKala A. 2011: Effects of photoperiodically induced reproductive diapause and cold hardening on the cold tolerance of Drosophila montana. - J. Insect Physiol. 57: 46-51.

Wheeler D.A., Hamblen-Coyle M.J., Dushay M.S. \& Hall J.C. 1993: Behavior in light-dark cycles of Drosophila mutants that are arrhythmic, blind, or both. - J. Biol. Rhythms 8: 67-94.

Wolda H. \& DenLinger D.L. 1984: Diapause in a large aggregation of a tropical beetle. - Ecol. Entomol. 9: 217-230.

YAmaguchi K. \& Goto S.G. 2019: Distinct physiological mechanisms induce latitudinal and sexual differences in the photoperiodic induction of diapause in a fly. $-J$. Biol. Rhythms 20: $1-14$.

Zhu D.-H. \& TANaKa S. 2004: Summer diapause and nymphal growth in a subtropical cockroach: response to changing photoperiod. - Physiol. Entomol. 29: 78-83.

Received June 2, 2020; revised and accepted July 28, 2020 Published online August 10, 2020 